\title{
XLIX. The ice of Greenland and the antarctic continent not due to elevation of the land
}

\author{
James Croll LL.D. F.R.S.
}

To cite this article: James Croll LL.D. F.R.S. (1883) XLIX. The ice of Greenland and the antarctic continent not due to elevation of the land , Philosophical Magazine Series 5, 16:101, 351-360, DOI: $10.1080 / 14786448308627444$

To link to this article: http://dx.doi.org/10.1080/14786448308627444

Published online: 28 Apr 2009.

Submit your article to this journal $₫$

Џ Article views: 5

Q View related articles $\square$ 
XIIX. The Ice of Greenland and the Antarctic Continent not due to Elevation of the Land. By James Croll, LL.D., F.R.S.*

GEENLAND.-The only two continents on the globe covered by permanent ice and snow are Greenland and

the Antarctic. But are these continents to be regarded as Highlands or as Lowlands? It is an opinion held by many that these regions are greatly elevated, and that it is mainly owing to this elevation that they are so completely buried under ice. I have been wholly unable to find evidence for any such conclusion. It is of course true that, in regard to Greenland at least, the observations of Rink, Heyes, Nordenskjöld, Jensen, Brown, and others show that the upper surface of the inland ice is greatly elevated above the sea-level. Dr. Rink, for example, states that the elevation of this icy plain, at its junction with the outskirts of the country where it begins to lower itself through the valleys, in the ramifications of the Bay of Omenak is about 2000 feet, from which it gradually rises towards the interior. Nordenskjöld, 30 miles from the coast, reached an elevation of 2200 feet, and found the ice continued to rise inwards. Heyes, who penetrated 50 miles into the interior, found the elevation about 5000 feet, and still continuing to slope upwards towards the interior of the continent. This upward slope is a necessary condition of continental ice, and must continue till the centre of dispersion is reached. As the larger portion of the Greenland ice is discharged at the west coast, it is probable that this centre of dispersion, or rather ice-shade, will lie nearer to the east coast than to the west. There is little doubt that the greater part of the surface of the inland ice is far above the snow-line; but this does not prove that Greenland is an elevated country, for this elevation of the upper surface of the ice may be due entirely to the thickness of the sheet. If the sheet is at least 1000 or 2000 feet thick at its edge, it is not surprising that it should be 5000 feet thick 50 miles in the interior, seeing that it is a physical and mechanical necessity that continental ice should gradually thicken towards the centre of dispersion. It has been shown from physical considerations ('Climate and Time,' pp. 374-386) that the thickness of the ice in the centre of Greenland is probably upwards of 2 miles, and that the Antarctic ice-cap at the South Pole, which is most likely not far from the centre of dispersion, must be over 6 miles in thickness.

* Communicated by the Author. 
Certainly no one has ever seen, and probably no one ever will see, elevated land under the ice either of Greenland or the Antarctic continent; and to assume its existence because those regions are so completely glaciated would simply be to beg the very question at issue.

It will doubtless be urged that, although the ground under the ice may not be elevated, yet there may be lofty mountainchains in the interior which might account for the origin of the ice. We have, I think, good grounds for concluding that if there are mountain-ranges in the interior of Greenland (of which there is absolutely no proof, although one or two isolated peaks have been seen), they must be wholly buried under the ice. For if mountain-masses rise above the icy mantle, there ought to be evidence of this in the form of broken rock, stones, earth, and other moraine matter lying on the inland ice. "But as soon as we leave the immediate vicinity of the coast," says Dr. Brown, "no moraine is seen coming over the inland ice. No living creature, animal or plant, except a minute alga." This could not possibly be the case if ranges of mountains rose above the general ice-covering. These mountain-ranges, if they exist, are doubtless covered with snow and their sides with glaciers; but this would not prevent pieces of broken rock and stones from rolling down upon the inland ice. In fact it would have the very opposite result; for glaciers would be one of the most effective agents possible in bringing down such material, and it is certain that no avalanche of snow could take place without carrying along with it masses of stones and rubbish. All these materials brought down from the sides of the projecting peaks would be deposited on the surface of the inland ice and carried along with it in its outward motion from the centre of dispersion, and could not fail to be observed did they exist. The fact that no such thing is ever seen is conclusive proof that these supposed projecting mountain-ranges do not exist.

But it may still be urged that the absence of moraine matter on the surface of the inland ice is not sufficient evidence that they do not exist; for as this material from the interior would have to travel hundreds of miles before reaching the outskirts, a journey occupying a period of many vears, the stones would become buried under the successive layers of ice formed on the surface during their passage outwards. But supposing this were the case, these buried moraines, if they existed, ought to be seen projecting from the edge of the sheet at places where icebergs break off, and also on the edges of the icebergs themselves near to their tops; but such, I presume, is never the case. Further, as the inland ice has to force its 
way through the comparatively narrow fjords before reaching the sea, the moraines could not fail to be occasionally observed did they exist.

But supposing there were mountains in the interior, this would not account for the general ice-covering. It would not account for the intervening spaces between the mountains being filled up with ice. To account for the whole country being covered with ice through the influence of mountains, we should have to assume that it was studded over with them at no great distance from one another; otherwise all that we should have would simply be local glaciers.

Dr. Robert lirown, one of the highest authorities in matters relating to Greenland, who does not believe in the existence of mountain-masses in the interior, says :- " " I do not think a range of mountains at all necessary for the formation of this huge mer de glace, for this idea is derived from the Alpine and other mountain-ranges, where the glacial system is a petty affair compared with that of Greenland. I look upon Greenland," he continues, "and its interior ice-field in the light of a broad-lipped shallow vessel, but with breaks in the lip here and there, and the glacier like some viscous matter in it. As more is poured in, the viscous matter will run over the edges, naturally taking the line of the chinks as its line of outflow. The broad lips of the vessel, in my homely simile, are the outlying islands or 'outskirts;' the viscous matter in the vessel, the inland ice ; the additional matter continually being poured in, the enormous snow-covering, which, winter after winter, for seven or eight months in the year, falls almost continuously on it; and the chinks or breaks in the vessel are the fjords or valleys down which the glaciers, representing the outflowing viscous matter, empty the surplus of the ressel" *.

In North Greenland and along Smith Sound a warm southeast wind, somewhat similar to the Föhn of Switzerland, has been reported in the middle of winter. From this it has been inferred by some that there must be high ranges of mountains in the interior from which this wind descends. There are, however, certainly no good grounds for such a conclusion; for we know that the upper surface of the inland ice of North Greenland, 50 or 100 miles from the outskirts, has an elevation of at least 4000 or 5000 feet. Now a wind crossing this icy plateau and descending to the sea-level would have its temperature raised by upwards of $20^{\circ}$, and also its capacity for moisture at the same time greatly increased. The consequence would therefore be that, in the midst of a Greenland winter, such a wind would be felt to be hot and dry.

* 'Arctic Papers for the Expedition of 1875,' p. 24.

Phil. Mag. S. 5. Vol. 16. No. 101. Nov. 1883. 2 C 
The opinion was expressed by Giesecke, who long resided in Greenland, that that country is merely a collection of islands fused together by ice. This opinion is concurred in by Dr. Brown, who says that "most likely it will be found that Greenland will end in a broken series of islands forming a Polar archipelago. That the continent (?) is itself a series of such islands and islets-consolidated by means of the inland ice-I have already shown to be highly probable, if not absolutely certain, as Giesecke and Scoresby affirmed." It has long been a belief that several of the west-coast fjords cut through Greenland from sea to sea-in short, that they are simply straits filled up with ice. The important bearing that this island-condition of Greenland has on the explanation of the warm interglacial periods of that country will be shown in a future article.

Antarctic Regions.-It needly hardly be remarked, that what has been stated as to the total absence of proof that Greenland possesses elevated plateaus and ranges of lofty mountains holds in a still more marked degree in reference to the Antarctic continent. Here is a region nearly 3000 miles across, buried under ice, on which the foot of man never trod. There is not the shadow of a ground for concluding that the interior of this immense region is, under the ice, greatly elevated, or that it possesses lofty mountain-ranges. The probability seems rather to be that, like Greenland, the area, as Sir Wyville Thomson supposes, consists of comparatively low dismembered land or groups of islands bound together by a continuous sheet of ice. "We have no evidence," says Sir Wyville, "that this space, which includes an area of about 4,500,000 square miles, nearly double that of Australia, is continuous land. The presumption would seem rather to be that it is at all events greatly broken up; a large portion of it probably consisting of groups of low islands united and combined by an extension of the ice-sheet."

"Various patches of Antarctic land," he continues, "are now known with certainty, most of them between the parallels of $65^{\circ}$ and $70^{\circ} \mathrm{S}$.; most of these are comparatively low, their height, including the thickness of their ice-covering, rarely exceeding 2000 to 3000 feet. The exceptions to this rule are the volcanic chain, stretching from Balleny Island to latitude $78^{\circ} \mathrm{S} . ;$ and a group of land between $55^{\circ}$ and $95^{\circ}$ west longitude, including Peter the Great Island, Alexander Land, Grabam Land, Adelaide Island, and Louis Philippe Land. The remaining Antarctic Land, including Adelie Land, Clairie Land, Sabrina Land, Kemp Land, and Enderby Land, nowhere rises to any great height" .

* 'Lecture on Antarctic Regions' (Collins, Glasgow, 1877); 'Nature,' vol. $x$. 
There is another class of facts which shows still more conclusively the probably low flat nature of most of the Antarctic regions. I refer to the character of the great ice-barrier, and the bergs which break off from it. The icebergs of the southern ocean are almost all of the tabular form, and their surface is perfectly level, and parallel with the surface of the sea. The icebergs are all stratified; the stratifications run parallel with the surface of the berg. The stratified beds, as we may call them, are separated from each other by a well-marked blue band. These blue lines or bands, as Sir Wyville Thomson remarks, are the sections of sheets of clear ice; while the white intervening spaces between them are the sections of layers of ice where the particles are not in such close contact and probably contain some air. The blue bands, as Sir Wyville suggests, probably represent portions of the snow surface which during the heat of summer becomes partially melted and refrozen into compact ice; while the intervening white portions represent the snow of the greater part of the year, which of course would become converted into ice without ever being actually melted. It is therefore more than probable that each bed with its corresponding blue band may represent the formation of one year. Judging from the number of these layers in an iceberg, some of these layers must be of immense age, occupying a period probably of several thousand years in their formation. And as the ice is in a constant state of motion outwards from the centre of dispersion-probably the South Pole-the bergs before becoming detached from their parent mass must have traversed a distance of hundreds of miles.

The fact that these bergs must have travelled from great distances in the interior is further evident from the following consideration. The distance between the well-marked blue lines is greatest near the top of the berg, where it may be a foot or more, and becomes less and less as we descend, until, near the surface of the water, it is not more than two or three inches. This diminution in the thickness of the ice-strata from the top downwards has been considered by Sir Wyville to be mainly due to two causes-compression, and melting of the ice, particularly the latter. But in my paper on the Antarctic Ice (Quart. Journ. of Science, Jan. 1879) I have shown that, although compression and melting may have had something to do in the matter, this thinning of the strata from the top downwards is a necessary physical consequence of continental ice radiating from a centre of dispersion. Assuming the South Pole to be this centre, a layer which in, say, latitude $85^{\circ}$ covers 1 square foot of surface will, on reaching latitude $80^{\circ}$, cover 2 square feet; at latitude $70^{\circ}$ it will $2 \mathrm{C} 2$ 
occupy 4 square feet, and at latitude $60^{\circ}$ the space covered will be 6 square feet. Then if the layer was 1 foot thick at latitude $85^{\circ}$, it would be only 6 inches thick at latitude $80^{\circ}$, 3 inches thick at latitude $70^{\circ}$, and 2 inches at latitude $60^{\circ}$. Had the square foot of ice come from latitude $89^{\circ}$ it would occupy 30 square feet by the time it reached latitude $60^{\circ}$, and its thickness would be reduced to $\frac{1}{30}$ of a foct, or $\frac{2}{5}$ of an inch.

Now the lower the layer the older it is, and the greater the distance which it has travelled. A layer near the bottom may have been travelling from the Pole for the past 10,000 or 15,000 years, whereas a layer near the top may perbaps not be 20 years old, and may not have travelled the distance of a mile. The ice at the bottom of a berg may have come from near the Pole, whereas the ice at the top may not have travelled 100 yards.

There is still another consideration which must be taken into account. It is this: the icebergs all seem to bear the mark of their original structure, and the horizontal stratifications appear also never to have been materially altered in their passage from the interior. This fact seems to have struck Sir Wyville forcibly. "I never saw," he says, "a single instance of deviation from the horizontal and symmetrical stratification which could in any way be referred to original structure; which could not, in fact, be at once accounted for by changes which we had an opportunity of observing taking place in the icebergs. There was not, so far as we could see, in any iceberg the slightest trace of structure stamped upon the ice in passing down a valley, or during its passage over roches moutonnées or any other form of uneven land; the only structure except the parallel stratifications which we ever observed which could be regarded as bearing upon the mode of original formation of the ice-mass, was an occasional local thinning-out of some of the layers and thickening of others, just such an appearance as might be expected to result from the occasional drifting of large beds of snow before they have time to become consolidated."

There cannot, I think, be the shadow of a doubt that these thin horizontal bands of clear blue ice, with their less dense and white intervening beds, are the original structure of the bergs. And it is evident that if the ice had crossed mountainridges, valleys, or other obstructions in the course of its journey from the interior, these beds could not have avoided being crushed, fractured, broken up, and mixed together. Had this happened, it would have been physically impossible that they could ever have been restored to their old positions. Ice is, no doubt, plastic, and pressure, along with motion, 
might perhaps induce fresh lines of stratification; but neither motion nor pressure could have selected broken blue bands from among the white and placed them in their old positions.

Why the icebergs from Greenland are not of the tabular form and stratified like those of the Antarctic regions, is doubtless owing to the fact that the Greenland ice is discharged through narrow fjords, which completely destroy the original horizontal stratifications.

Let us now see the consequence to which the foregoing considerations all lead. The tabular form and flat-topped character of the icebergs, with their perfectly horizontal bedding, show that they have been formed on a flat and even surface. They show also that this flat surface is not a mere local affair, but that it must be the general character of the Antaretic land ; for all, or nearly all, of the bergs are of this tabular form. Again, the unaltered character of the stratifications of the bergs shows that there can be no great mountain-ranges, or even much rough and uneven ground in the interior; for if there were, the bergs in their passage outwards would have had to pass over it; and this they could not have done and still have retained, as they actually have, their horizontal stratifications undisturbed. These icebergs, as we have seen, must have traversed in their outward motion, before being disconnected with the ice-sheet, a distance of hundreds of miles; yet none of them bear the marks of having passed down or across a valley or even over roclies moutonnées.

That the Antaretic continent has a flat and even surface, the character of the icebergs shows beyond dispute. But this, it will be urged, does not prove that this surface may not be greatly elevated; in other words, that it may not be a flat elevated plateau. This, of course, is true ; but it is evidently far more likely that this region, nearly 3000 miles across, should consist of flat dismembered land, or groups of low islands separated and surrounded by shallow seas, than that it should consist of a lofty plateau without either hills, valleys, or mountain-ridges. In this case it may be that the greater part of the Antarctic ice-cap rests on land actually below sealevel-viz. on the floor of the shallow seas surrounding those island-groups. We know that such a condition of things was actually the case in regard to the great ice-sheet of Northwestern Europe during the glacial epoch. A glance at the Chart of the path of the ice given in 'Climate and Time,' p. 448 (which since its publication has been proved to be correct in almost every particular), will show that the larger portion of the sheet rested on the bed of the Baltic, German Ocean, and the seas around Great Britain and Ireland and the Orkney 
and Shetland islands. That the Antaretic ice was formed on low and flat land bordered for considerable distances by shoal water was the opinion also of Sir Wyville Thomson.

Assuming then, what seems thus probable, that the Antarctic regions consist of low discontinuons land, it will belp to explain, as will be shown in a future paper, the disappearance of the ice during the warm interglacial periods of the southern hemisphere.

On the Argument against the Existence of a South-Polar Icecap.-We have certainly no evidence that during even the severest part of the glacial epoch an ice-cap, like that advocated by Agassiz and other extreme glacialists, ever existed at the North Pole : I am, however, unable to admit with Mr. Alfred R. Wallace that some such cap, though of smaller dimensions, does not at present exist at the South Pole. Speaking of the Antarctic ice-cap, Mr. Wallace says :- "A similar ice-cap is, however, believed to exist on the Antarctic Pole at the present day. We have, however, shown that the production of any such ice-cap is improbable, if not impossible; because snow and ice can only accumulate where precipitation is greater than melting and evaporation, and this is never the case except in areas exposed to the full influence of the vapourbearing winds. The outer rim of the ice-sheet would inevitably exhaust the air of so much of its moisture, that what reached the inner parts would produce far less snow than would be melted by the long hot days of summer"*.

This opinion, that the mass of ice is probably greatest at the outer rim, which of course is most exposed to moist winds, and that it gradually becomes less and less as we proceed inwards till at last it disappears altogether, is by no means an uncommon one. At the present moment while I write (July 9th), Professor Nordenskjöld is probably attempting to cross the inland ice of Greenland with the hope of finding in the interior, hills, valleys, and green fields completely free from ice.

It by no means follows, as some might be apt to suppose, that the ice must be thickest where the snowfall is greatest. In case of continental ice the greatest thickness must always be at the centre of dispersion; but it is here that, owing to distance from the ocean, the snowfall is likely to be least.

We have no reason to believe that the quantity of snow falling, at least at the South Pole, is not considerable. Lieut.

* 'Island Life,' p. 156. I am unable to reconcile the above altogether with what Mr. Wallace says at page 132, where he refers approvingly to my statement that the Antarctic ice-sheet has been proved to be in some places at least over a mile in thickness at the edge, and that it must conequently be far thicker inland. 
Wilkes estimated the snowfall of the Antarctic regions to be about 30 feet per annum; and Sir John Ross says that during a whole month they had only three days free from snow. But there is one circumstance which must tend to make the snowfall near the South Pole considerable, and that is the inflow of moist winds in all directions towards it; and as the area on which these currents deposit their snow becomes less and less as the Pole is reached, this must, to a corresponding extent, increase the quantity of snow falling on a given area. Let us assume, for example, that the clouds in passing from lat. $60^{\circ}$ to lat. $80^{\circ}$ deposit moisture sufficient to produce, say, 30 f'eet of snow per annum, and supposing that by the time they reach lat. $80^{\circ}$ they are in possession of only one tenth part of their original store of moisture, still, as the area between lat. $80^{\circ}$ and the Pole is but one eighth of that between lat. $60^{\circ}$ and $80^{\circ}$, this would notwithstanding give 24 feet as the annual amount of snowfall between lat. $80^{\circ}$ and the Pole.

However small may be the snowfall, and consequent amount of ice formed annually around the South Pole, unless it all melted it must of necessity accumulate year by year till the sheet becomes thickest there; for the ice could not move out of its position till this were the case. But supposing there were no snow whatever falling at the Pole and no ice being formed there, still this would not alter this state of matters; for in this case the ice forming at some distance from the Pole all around would flow back towards the centre, and continue to accumulate there till the resistance to the inward flow became greater than the resistance to the outward; but this state would not be reached till the ice became at least as thick on the poleward as on the outward side. There is no evading of this conclusion unless we assume, what is certainly very improbable, if not impossible, viz. that the ice flowing polewards should melt as rapidly as it advances. We know, however, that in respect to the ice which flows outwards towards the sea little, if any, of it is melted; and it is only after it breaks off in the form of bergs and floats to warmer latitudes that it disappears, and that eren with difficulty. It is therefore not likely that the ice flowing inwards towards the Pole, and without the advantage of escape in the form of bergs, should all happen to melt. If little or none of the ice flowing toward the Eiquator melts, it is physically impossible that all the ice flowing polewards should manage to do so; and if it did not all melt, it wonld accumulate year by year around the Pole till it aequired a thickness sufficient to prevent any further How in that direction, or, in other words, till its thickness at the Pole became as great as it is all around. 
The opinion that the great mass of the ice on the Antarctic continent and also on Greenland lies near to the outer edge, and that it gradually diminishes inwards till at last it disappears, is evidently one based on a misapprehension as to the physical conditions of continental ice. I cannot help believing that had Professor Nordenskjöld duly reflected on the necessary physical and mechanical conditions of the problem which he is endeavouring to solve, he would not have undertaken the journey across the Greenland ice.

Note, September 22nd.-Baron Nordenskjöld has just returned, and, as might have been expected, be found the interior of Greenland a desert of ice, with the icy plain gradually sloping upwards to the interior. The ice rose at the furthest spot reached ( 280 miles from the coast) to 7000 feet above the sea, and was still seen to rise to the east. The results of the expedition are, however, of the most important character, confirming, as they do, the true theory of continental ice.

L. The Method of Least Squares. By F. Y. EDGEwortн, M.A., Lecturer on Logic at King's College, London*.

I.

THE Law of Error and the Method of Least Squares do not traverse the same ground; and the direction of the one course of reasoning is inverse to that of the other. In the former we derive the formation of a source $\dagger$ of error from the confluence of an indefinite number of small tributaries. In the latter we start from a position lower down on the stream of causation, from observations resulting from a source of error, and reason up from given observations (accompanied with some knowledge of the source of error from which they result) to (a more complete knowledge of) the source of error, the facility-curve under which the observations range themselves. For example:-Given $x_{1}, x_{2}$, \&c. observations diverging according to a probability-curve of known modulus, but unknown centre, to determine the centre. These distinctions are likely to recommend themselves to those who have studied Mr. Glaisher's article and other first-rate anthorities. But there is another distinction, more interesting to the philo-

* Communicated by the Author.

$\dagger$ According to the received view, one particular source-the probabilitycurve; according to our views, a great variety of facility-curves (see previous paper). 